\title{
ERRATUM
}

\section{Erratum to: NMR resonance assignment of DnaE intein from Nostoc punctiforme}

\section{Kimmo Heinämäki $\cdot$ Jesper S. Oeemig • \\ Kimmo Pääkkönen · Janica Djupsjöbacka • \\ Hideo Iwaï}

Published online: 20 November 2012

(C) Springer Science+Business Media Dordrecht 2012

\section{Erratum to: Biomol NMR Assign}

DOI 10.1007/s12104-008-9137-1

There was an error in labeling of "N131" in the $\left[{ }^{1} \mathrm{H},{ }^{15} \mathrm{~N}\right]$ HSQC spectrum (Fig. 1). The corrected Fig. 1 is presented in this article. The third author's name is also included after reassessment of the contributions. The corrected author list is given in this article.

The online version of the original article can be found under doi:10.1007/s12104-008-9137-1.

K. Heinämäki · J. S. Oeemig · K. Pääkkönen · J. Djupsjöbacka ·

H. Iwaï $(\square)$

Research Program in Structural Biology and Biophysics, Institute

of Biotechnology, University of Helsinki, P.O. Box 65,

Helsinki 00014, Finland

e-mail: hideo.iwai@helsinki.fi 


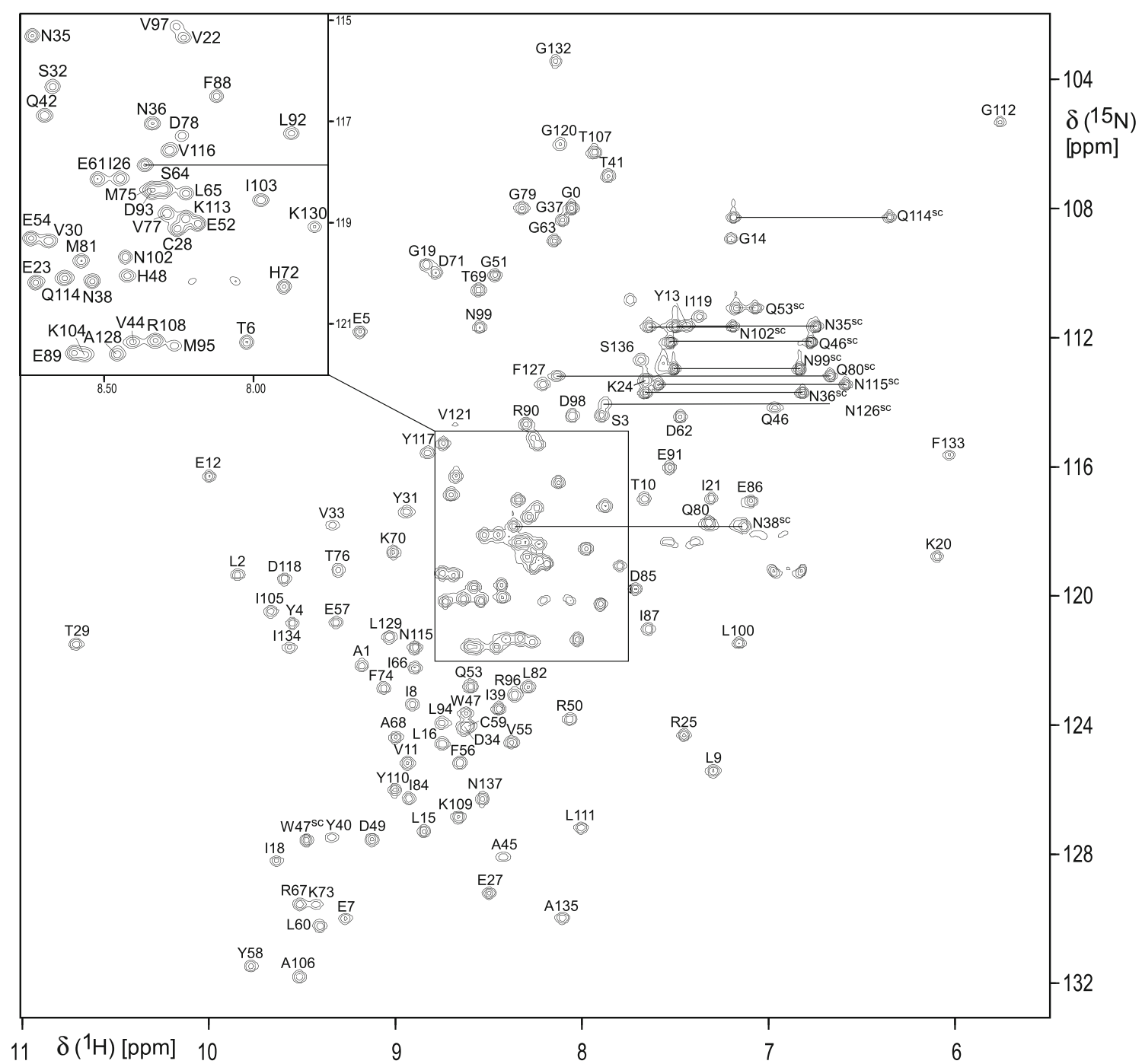

Fig. 1 Two-dimensional $\left[{ }^{1} \mathrm{H},{ }^{15} \mathrm{~N}\right]-\mathrm{HSQC}$ spectrum of $2 \mathrm{mM}$ single chain $\mathrm{NpuDnaE}$ intein in $10 \mathrm{mM}$ sodium phosphate buffer at $\mathrm{pH} 6.0$ at $298 \mathrm{~K}$. The spectrum was recorded at ${ }^{1} \mathrm{H}$ frequency of $600 \mathrm{MHz}$. A total of $100\left(\omega_{1}\right) \times 683\left(\omega_{2}\right)$ complex points were collected for this spectrum, with $\mathrm{t}_{1, \max }=18.2 \mathrm{~ms}, \mathrm{t}_{2, \max }=32.0 \mathrm{~ms}$. The assignments are indicated by the number and one character codes for 20 amino acids. The side-chain resonances are marked by $s c$. The side-chain amide groups of asparagines and glutamines are connected by horizontal lines 